\title{
The Effect of Adventure-Based Counseling Modules on Self-Efficacy of College Students Council (CSC) in Sultan Idris Education University
}

\author{
Nuzsep Almigo \\ Universiti Pendidikan Sultan Idris, Malaysia \\ Nandang Rusmana, Anne Hafina, Yusi Riksa Yustiana and Dodi Suryana \\ Universitas Pendidikan, Indonesia
}

\begin{abstract}
The purpose of this study is to find out the effect of adventurebased counseling modules on the self-efficacy of the College Students Council (CSC). Self-efficacy is the feeling, confidence, perception, and belief in the ability to cope with a particular situation that will influence the way an individual change it condition. Besides, Self-efficacy is measured by the test validity and reliability as well as its effectiveness is evaluated through a research instrument self-efficacy questionnaire consisting of four main factors, namely cognitive, affective, motivational, and selective. Adventure-based counseling is a modulebased training in the form of game simulations made based on real-life situations on our daily life and given reflection after performing simulation activities, which is the method of treatment to the study sample. The study design was a one-group pretest-posttest design involving. The results show that there is an effect of taking the adventure-based module on the self-efficacy of the students, indicating that there was a significant difference in self-efficacy before and after the adventure-based counseling module $(p=0.00)$. An adventure-based counseling module is a module training that has undergone research and become one of the student's resource development programs. The results of this study can also assist the management of residential colleges in designing quality activities for the students.
\end{abstract}

Keywords: Adventure-based counseling; Self-efficacy.

\section{Introduction}

The role of an individual in the organization is significant as an effort to enhance the organization's success in achieving its goals. Perseverance in the workforce is an essential factor for the progress of the organization to become more 
successful. The problem is that in the organization is deficient, and it is proved to be a lot that many individuals meet only the prerequisites, such as for certificates, finances, and social status. Often these issues have an impact on the productivity of an organization. Thus, if not treated properly, then the organization is likely to experience a significant decline. Studied (Stajkovic \& Luthans, 1998) the relationship between organizational commitment and intention to quit among workers, the data analysis result shows that organizational commitment has a significant relationship with the aim to leave.

University is a place where students continue their studies. A university must have various positions in both academic and non-academic. University member has an important role. The research (Bandura \& Locke, 2003; Sparks, Ajzen, \& Hall-box, 2002) have observed and found that there is a relationship between job satisfaction and organizational commitment between public and private universities. Each role of an individual in the organization will want to work towards increasing the university's productivity, includes the College Student Council of the residential college. Moreover, the College Student Council (CSC) provides roles and contributions to residential college students and programs to be conducted both within and outside of UPSI. Therefore, each member should hold this role with a strong sense of responsibility and commitment in themselves.

High self-efficacy helps calm feelings in approaching difficult tasks and activities (Chahine, 2015). On the other hand, people who doubt their abilities can believe that something is more complicated (Taufik, Yudha, \& Suryana, 2019). Based on Sandi's (2017) study of the Relationship of Self-Effectiveness with Student Learning Interests - the results show that there is a relationship between selfefficacy and learning interest in YPK Southeast students indicates that selfefficacy is closely related to student interest. Baron and Byrne (2004) revealed that when an individual has confidence in his or her ability to cope with anxiety, the body produces natural and safe remedies, which can reduce stress and improve performance. An individual who is confident in his or her environment is capable of coping with the situation and the context in which he or she is dealing with the individual, the individual will feel at ease and not worry, and will be able to think clearly. Individuals with low Self-efficacy are individuals who are incapable, vulnerable, anxious, and shy away from challenges and tasks, sensitive to stressful situations, lack of commitment, and slow recovery (Bandura, 1997; Bangcola, n.d.; Rusmana, 2019; Tho, Dong, \& Noi, 2015).

One of the most essential self-regulation skills of a student representative is cognitive restructuring skills and stimulus control which is self-efficacy (LeversLandis, C.E, Burant C., Drotar D., Morgan L., Trapl, E.S, Kwoh, C, K, 2003; Resnicow, K., Davis, M., Smith, M., Baranowski, T., Lin, L.S., Baranowski, J., Doyle, C, \& Wang, D.T, 1997). Self-Efficacy is a belief in one's effectiveness in performing specific tasks consistent with cognitive, social theory (People, 2017). However, it is also possible that a university student's organization has experienced similar problems with this self-efficacy. If there are deficiencies in the performance of duties as a member of the organization, then it will affect the 
productivity of the organization. The situation, as illustrated, shows that human factors play an active role in improving the quality of the organization. Furthermore, based on the phenomenon exists, UPSI students who have the experience, they suffer from the same problem about the lack of a sense of responsibility and commitment. In this regard, this phenomenon can be detrimental and undermines organizational goals. In line with the findings (Greason \& Cashwell, 2009; Lee, 2015) which stated that human resources are the most important asset and have the greatest contribution to the success of an organization.

Adventure-based counseling $(\mathrm{ABC})$ is a group-oriented program that helps participants learn to improve their self-awareness, accept responsibility for their choices, act as they wish, and emphasize potential customers. This result is in line with the principles of invasive theory in which the presence of a combination of two approaches offers unique opportunities to help individuals achieve positive therapeutic outcomes (Scott, 2009). According to Moote \& Wodarsky (in Glass, 2001), experiential technique counseling, as well as adventure-based counseling is a group activity focused on developing teamwork and enhancing interpersonal skills and adolescent self-esteem. The results of Page \& Chandler's study (in Glass, 2001) show that there is an increase in student self-esteem as a result of group activity. Classroom unity can be developed when groups are asked to collaborate on various tasks, and adventure-based counseling is one of the methods. Adventure-based counseling uses expressive education in the outdoors to enhance self-esteem, trust in others, and positive student behavior (Glass, 2001).

Adventure-based counseling ( $A B C)$ is a mix of learning through experience, outdoor education, and group counseling (Gillis \& Simpson, 1994). Adventure therapy is the use of games, activities, initiatives, and skills to facilitate group process development, interpersonal relationships, personal growth, and therapeutic benefits. (Ashby, Kottman, \& DeGraaf, 2008). The Adventure-based counseling program uses non-competitive tasks and emphasizes the interactions between experts to complement each other. Non-competitive activities are planted by incorporating elements of physical and mental challenges so that success cannot be achieved individually. Therefore, social skills and the ability to work in groups are critical (Glass, 2001).

Additionally, behavioral changes can be implemented, practiced, and processed through adventure-based counseling program activities. Although Adventurebased counseling is developed as a program in a wilderness setting, it can adapt to a variety of environments, including schools. For example, school counselors may want to provide groups with a focus on peer relationships, leadership training, self-defense, social skills development (Nassar-McMillan and Cashwell in Glass \& Shoffner, 2001). One of the training programs available at UPSI is the Adventure-Based Counseling (ABC) course, a program designed to enhance the values contained in organizations through work simulations in the form of games/activities. In the end, the activity was implemented in the form of reflection / debrief based on the game being performed (Kyriakopoulos, 2010). 
In this regard, studies should be conducted to look at the effectiveness of adventure-based counseling (ABC) module on self-efficacy towards the College Students Councils (CSC) in UPSI. Besides, the adventure-based counseling $(A B C)$ module aimed at reducing issues of self-efficacy at UPSI and promoting a team spirit of helping peers to overcome the problems related to the programmed at the College. Thus, this will result in better development of life among the CSC who are the student representatives and will able to implement a high impact programmed at the Colleges in the University as well.

\section{Method}

The research is survey studies that use the one-group pretest-posttest research design. Samples are from UPSI College students. The self-efficacy based on four factors of self-efficacy (Bandura \& Bandura, 2010; People, 2017): Cognitive (the ability to perceive positive and realistic ways of potential in carrying out tasks, obstacles or social desires); Affective (the ability to stabilize mental states, emotions and feelings); Motivation (the ability to maintain the level of seriousness and the period of effort to accomplish purposes or goals); Selective (the ability to face with social conditions and the adjustments with the environments or situations) (Bong \& Skaalvik, 2003; Werner \& Milyavskaya, n.d.). The questionnaire was distributed to research samples before and after the intervention of the adventure-based counseling module.

Adventure-based counseling modules have been confirmed to have reliability and validity and are already used at National Service Camp, UPSI, other agencies and schools in Malaysia. The intervention of adventure-based counseling modules was implemented for three days and two nights. There are nine slots altogether and are carried out in the form of simulations or games. The simulation or game activities are according to the real everyday life events, or in the organizations. In each of every slot, it consists of several elements that are suitable and acceptable in life, organizations or at the developmental level of teenagers or university students. The facilitators discussed during the activity and participants are asked to present based on what they have learned, and how to overcome the limitations and strength during the events. The analysis used was SPSS 21.0 for Windows 8.

Adventure-based counseling is an activity simulation that challenges individuals to develop a thinking, understanding, attitude, and the best way to act in solving problems that directly constitute a process of self-counseling (Almigo, 2012; (Ottander, Wilhelmsson, \& Lidestav, 2015). The adventure-based counseling method is a simulation activity in the form of a game in which each game has its own goals and objectives or goals to achieve as desired. Besides, the methods used in the Adventure Based Counselling module are:

a. Simulation activities come in the form of group or individual games, both indoor and outdoor.

b. Adventure/challenge groups or individuals.

c. A task from the games for each group and individual. 
d. The reflection is the link between the game/activity with organizational management, organizational culture, or in everyday life.

The adventure-based counseling module focuses on group ties because everyone has a different background, so the goals, desires, and expectations that a person has in life are also very different. Outcome (Hope that from the output that is received, it will have an impact on the self and can continue in daily life, it is will lead to more positive change and to develop and be able to motivate others).

The adventure-based counseling module implemented at UPSI is performed for three days and two nights with the concept of outdoor activities. There are several types of approaches and actions used in adventure-based counseling modules, namely: Cooperative activities and games (examples: balloon train, trust-building and more), Adventure trips (examples: camping, backpacking, mountain climbing, etc.), Solution initiatives problem (Example: Tower building). Each of these activities is designed to be therapeutic.

The methods of the adventure-based counseling module by slots in Table 1 .

Table 1. Slot in Adventure Based Counseling

\begin{tabular}{lc}
\hline & Method of Adventure Based Counseling Module \\
\hline Slot I & Ice Breaking + Debrief \\
Slot II & Full Value Contract + Debrief \\
Slot III & Games (Team Building) + Debrief \\
Slot IV & Games (Communication) + Debrief \\
Slot V & Games (Corporate Culture) + Debrief \\
Slot VI & Games (Group Task) + Debrief \\
Slot VII & Games (Application at Work) + Debrief \\
\hline
\end{tabular}

Details of adventure-based counseling module for each activity can be described as follows based on Table 1: Slot I - Ice Breaking Full Value Contract (The activity in this slot is intended to invite participants in the direction of their goals, trust and desire to achieve a specified goal); Slot II - Full Value Contract (The activities in this slot is to invite participants to the destination point, the trust and the desire to achieve the set targets; Slot III - Games Team Building (The activity in this slot is intended to invite participants into a stable and confident group formation). Slot IV - Communication (The event in this slot is designed to encourage participants to communicate as well as to use verbal or non-verbal language in full). Slot V - Corporate Culture (The activity in this slot is intended to invite participants to develop behaviors that are in line with the values and norms of the community or organization). Slot VI - Group Task (The activity of this slot is intended to invite participants to take full responsibility in working together or in the pursuit of trust). Slot VII - Application at Work (The activity in this slot is intended to invite participants to apply it in everyday life fully). 
Explanations of the meaning of adventure-based counseling: (1) Activities for group or individual training to select or test their creative thinking. Testing means evaluating what is done and learned and determining the result of thought in the form of creativity; (2) This activity is beneficial in revealing a more comfortable and more cost-effective way to explain problems if we discuss and think deeply. In showing an easy way to collaborate with others to achieve their goals,; (3) This adventure-based counseling can be associated with management games, leadership games, and problem-solving techniques (management games, leadership games, or problem-solving techniques). "Low ropes" activities also belong to the sport of creativity; (4) The program will build teams, which is the most popular and effective approach to management courses in team building. In this activity, all aspects of team culture will emphasize the following: leadership and follow-up functions, teamwork, communication, character, and attitude, thinking ability.

In addition, according to Almigo (2013) the objectives of adventure-based counseling modules are: Improve the ability of participants to work in groups; Improve the ability to motivate yourself and others; Increase mutual respect and mutual trust in each other; Helps provide psychological and emotional balance from the participants, while opening the door to become successful and progressive individuals; Minimize problems in the organization while also ensuring the program through the involvement of all participants; To produce dynamic team, knowledgeable and highly skilled in the pursuit of personal goals, groups and organizations.

Next is the method of reflection or debrief. In the adventure-based counseling module, these reflection methods and techniques can be done anywhere, whether in the room or in the shade outside so that the reflection conditions are more comfortable and calm. Therefore, reflection techniques should follow the following stages (Almigo, 2012):

a. Opening. The facilitator needs to explain the purpose of the meeting was to repeat the experience gained during the activity (Rusmana, 2019). The methods required in opening this reflection are: Participants are not forced to express what they have experienced or did not want, Conversations in the meeting are limited to the group or in other words confidential, Focus on conversations that have an impact and reaction from the participants.

b. Hope and reality. The Facilitator needs to make it clear that every hope he or she wants is not always fulfilled and must accept the existing fact. Expectations need to be simplified so that the goals are clear, and the goals can be achieved. That is why it is necessary to improve the element of consciousness and to try again.

c. Thoughts and Effects. The Facilitator should guide the participants to understand the meaning of the mind more clearly and to be able to feel the impression it receives. For example "can you explain what your true desire is?", "What do you do after finding out?", "How do you feel when you hold hands with your friends?" The purpose of the questions asked 
is to clarify the picture of what happened to him, to contemplate itself, and to help participants overcome the uncomfortable experience of life.

d. Defining emotional reactions. This is a tough time as the coach helps the coach to express the emotions that have engulfed in feelings of frustration, anger, anxiety, fear, helplessness, guilt, and helplessness. With the help of the coach, the participants are expected to feel comfortable and able to handle their questions and to be able to come back to life with a positive attitude.

e. Insight (deep understanding). The facilitator needs to make the participants accept what has happened to the participants, what they feel is normal, and most others do the same. It should be made clear that with an understanding of the actual incident, then the attitude that needs to take can be taken immediately.

f. Action. After the insight process, the facilitator needs to discuss ways to deal with the symptoms of self-esteem, such as overcoming frustration, overcoming anger. But keep in mind that coaches are a bridge for participants to find their way out. If the facilitator decides or solves the participants' problems, it is unlikely that the participant will accept them. Because of this, each challenge is different, and of course, the solution is different. Action alternatives, the facilitator can discuss other themes as additional insights for the participant if participants need further guidance, then they can refer to a specialist such as a psychologist, counselor, or clinical therapist.

The purpose of reflection, in general, is to raise awareness about what has been experienced in personal life in the real world. The use of this is to: Help formulate thoughts more easily. Screening is a process to see who needs more help. Here coaches can see quickly and accurately the problems experienced by the coaches, needing further support, disseminating excellent and up-to-date information and other educational things, reducing feelings of difference between participants and cohesion, and cooperation between experts is getting stronger.

\section{Results}

The results of Table 2, normality test samples using KS sample analysis (Kolmogorov Smirnov).

Table 2. Normality Test Samples

\begin{tabular}{lll}
\hline & $\mathbf{Z}$ & $\boldsymbol{p}$ \\
\hline Self-Efficacy & 0.819 & 0.513 \\
\hline
\end{tabular}

The results of the analysis using KS (Kolmogorov Smirnov) show that the distribution of the sample is normal. This is shown by $\mathrm{p}=0.513$ and $\mathrm{Z}=0.819$.

Table 3 shows the significant differences between self-efficacy scores of the College Students Council (CSC) in Sultan Idris Education University before and after joining adventure-based counseling modules, which is $p=0.00$. The rating 
before the intervention is $(\mathrm{M}=32.8, \mathrm{SD}=6.65)$, and after the invasion of adventure-based counseling, modules are $(\mathrm{M}=35.0, \mathrm{SD}=6.5)$.

Table 3. Paired Samples T-Test Self Efficacy before and after Adventure Based Counseling Module Intervention

\begin{tabular}{|c|c|c|c|c|c|c|}
\hline \multirow[t]{2}{*}{ Variable } & \multicolumn{2}{|c|}{$\begin{array}{c}\text { Before } \\
(\mathrm{n}=112)\end{array}$} & \multicolumn{2}{|c|}{$\begin{array}{c}\text { After } \\
(\mathrm{n}=112)\end{array}$} & \multirow[t]{2}{*}{$t(d f)$} & \multirow[t]{2}{*}{$p$-value } \\
\hline & $\mathbf{M}$ & SD & $\mathbf{M}$ & SD & & \\
\hline Self-Efficacy & 32.8 & 6.65 & 35.0 & 6.5 & $-3.32(111)$ & 0.00 \\
\hline Cognitive & 8.22 & 2.06 & 9.02 & 1.83 & $-3.80(111)$ & 0.00 \\
\hline Motivation & 8.03 & 1.86 & 8.60 & 1.92 & $-3.09(111)$ & 0.00 \\
\hline Affective & 7.93 & 1.95 & 8.40 & 2.04 & $-2.18(111)$ & 0.03 \\
\hline Selective & 8.40 & 2.09 & 9.05 & 1.97 & $-2.48(111)$ & 0.00 \\
\hline
\end{tabular}
$p<0.05 ; p<0.001 ;$

The results from the factors of Self-efficacy, which are (one), there is a significant difference in Cognitive factors before the intervention $(\mathrm{M}=8.22, \mathrm{SD}=2.06)$ and after an intervention $(\mathrm{M}=9.02, \mathrm{SD}=1.83)$. (Second), there is a substantial difference in Motivation factors before the intervention $(\mathrm{M}=8.03, \mathrm{SD}=1.86)$ and after the intervention $(\mathrm{M}=8.60, \mathrm{SD}=1.92)$. (Third), there is a considerable difference between Affective factors before the intervention ( $\mathrm{M}=7.93, \mathrm{SD}=1.95)$ and after the intervention $(\mathrm{M}=8.40, \mathrm{SD}=2.04)$. (Fourth), there is a substantial difference in Selective factors before the intervention $(\mathrm{M}=8.40, \mathrm{SD}=2.09)$ and after the intervention $(\mathrm{M}=9.05, \mathrm{SD}=1.97)$. Based on the analysis, that there are significant differences in self-efficacy before and after joining the adventurebased counseling modules, which are $(p=0.00)$ with an increment of 2.2. There is a difference in the increase in cognitive factor scores before and after the intervention is 0.8 , there is a difference in the increase in the score of motivational factors before and after the intervention is 0.57 , there is a difference in the increase in Affective factor scores before and after the intervention is 0.47 , and there is a difference in the increase in the score of the Selective factor before and after the intervention is 0.65 .

\section{Discussion and Conclusion}

According to the analysis, the researchers were able to identify an increase in self-efficacy before and after participating in an adventure-based counseling module. Self-efficacy is important during the implementation of adventurebased counseling modules towards the College Students Council (CSC). It is because the individuals that own high self-efficacy would be able to encounter the hurdles effectively (Blatti, Clinton, \& Graham, 2019; Rhodes, Cordie, \& Wooten, 2019), diligent at performing tasks, adapt to new situations, setting goals, have life strategies, and be ready whenever faced with the failure (Chen \& Gully, 2001). Meanwhile, individuals who have self-efficacy is low will easily sad, excessive worry, distancing themselves from the tasks that challenge, it is easy to give in to adversity, there is no commitment in life and slow to recover from the failure (Anderson, BS, Winett, RA, \& Wojcik, IR, 2000; Annesi, JJ, Unruh, JL, Marti, CN, Gorjala, S., Tennant, G., 2011). 
College students who took part in the College Students Council (CSC) are more confident and able to face up with the challenges in life. University students are at the adolescence stage in which they are still going through with the developmental processes. If students are unable to resolve the problem or the task of development, the development process will be affected, such as disruptions in confidence, the feeling is not liked by others, feeling abandoned by colleagues, and also feels uncomfortable, and especially the status of the student is on the College Students Council (CSC). The individual will feel difficult when being active as an example, maintaining the relationship according to the environment. It is being the reason why teenagers unable to think creatively, do not want to get acquainted with other people as they perceive themselves as lacking the skills to solve problems (Nowak, 2019). Hence, a new programmed is needed to help teenagers to deal with this matter.

Based on self-efficacy aspects, cognitive is the ability to perceive positive and realistic ways of potential in carrying out tasks, obstacles, or social desires (Clark, M. M, Cargill, B. R, Medeiros, M. L, \& Pera, V., 1996). It shows that action starts from thinking positive things such as success or it could also be imagining failure (Bandura, 1997). According to adventure-based counseling modules, participants will have positive thoughts on how to improve quality of life, learn more about healthy concepts, and how to develop confidence (City, 2015; Sidiropoulou-dimakakou \& Mylonas, 2015). Next, Effective is the ability to stabilize mental states, emotions, and feelings. It enables participants to control life situations and not to perceive things negatively. Motivation is the ability to maintain the level of seriousness and the period of effort to accomplish purposes or goals (Flammer, 2015; Sparks et al., 2002). Motivation is beneficial for the self and also to help other people as it could strengthen the self-belief and to control the current situation (Elstad, 2017). Lastly, selective is the ability to face with social conditions and the adjustments with the environments or situations. Participants who are voluntarily taking part in this programmed will tend to feel a confidence that they have the best decision to accomplish success (Bong \& Skaalvik, 2003; Hermans, 2014).

One of the goals adventure-based counseling is to increase self-efficacy UPSI student, this is in line with Human (2012) which states that the student selfefficacy tend to get involved with tasks challenging and have a high selfmotivation. This statement is supported by (Bentsen \& Jensen, 2012; Duindam, 1994; Sparks et al., 2002) wherein his research, teenagers with high confidence levels are easily adapted to the new environment. They can take part in diet programmed as a method to create something desirable. University students that involve in this programmed will show high spirit and confidence and also have believed that this module can increase self-efficacy and have better lifestyles (Sparks et al., 2002).

Adventure-based counseling can be adapted in schools to help students develop skills in problem-solving, leadership, and low-cost listening because the format is not necessarily in the outdoor setting. Additionally, a school counselor can 
plan, organize, facilitate, and evaluate student group performance during this Adventure based counseling program (Wagner \& Elliott, 2014). An adventurebased counseling approach can be applied in schools. Some studies show that programs of adventure-based counseling can increase the level of self-efficacy and self-concept (Connelly, 2012) and self-esteem (Wagner \& Elliot, 2014). Besides, the results of the adventure-based counseling program are not influenced by other students' demographic factors such as socioeconomic status, age, and gender (Connelly, 2012), making the Adventure-based counseling program ideal for running in the school environment. According to Carson (2015), the purpose of adventure-based counseling is to improve self-esteem and self-esteem, control anger, responsibility, challenge inappropriate behavior, respect individual differences, communicate with others, solve problems, trust in others, and group, have social maturity, and participate in physical activity.

One of the goodness of adventure-based counseling modules is debriefed/reflection section at each of the activities. (Carlson \& Cook, 2007; Gillen \& Balkin, 2017; Ragsdale, Cox, Finn, \& Eisler, 1996) Mentioned that reflection is the inner-self thing (potentially to become outer-self thing such a mentor), and it can affect our emotions. Reflection/debrief us to recall previous events and make us react to it. In this situation, reflection helps a coach to summarize what had happened and take lessons from that, either mistakes or the right things (Roth, 2016). In sum, adventure-based counseling modules initially are a simulation of real-world or everyday lives that are counseling into "game," and after that, it is transformed back to real-world (work) as in the form of reflection (debrief) (Armitage \& Conner, 2001; Hermans, 2014).

This study uses the features of a research study to critique and refine the first elements of the explanatory model developed in earlier stages. Some aspects of the service are to enhance the reliability of the conceptual findings (smaller segments of the transcript, clearer articulation of module elements, module element refinement, and observational support triangulations. Previously found a way to generalize samples in the same population and reinforce fine-tuning modules, so this study has shown that problem-solving frameworks can be a useful tool in problem-solving directions. It is a one-solution framework that includes a meta-cognitive process that can be a more effective tool in issue instructions.

This study has also made a profound impact in terms of work practices at UPSI. This study highlights the need to attend to contextual issues in organizational stress and well-being interventions. It suggests that management may need to implement new strategies and/or promote existing stress management and reduction strategies for academics, and their employees are either new to the university or those who have worked for the organization for a more extended period of time to ensure that they are aware of organizational strategies to promote employee well-being and enthusiasm in their work environment.

The result of this study shows that the implementation of adventure-based counseling modules towards the College Students Council (CSC) students in 
UPSI has a high impact. The positive result in a student indicates an increase in thinking style, motivational level, affective, and selective in developing trust towards self and future success (Taft, Hotchkiss, \& Lee, 2016). Throughout this programmed, students of the College Students Council (CSC) are expected to be able to face the difficulties and also could maintain the right result after this program later. Adventure-based counseling modules created according to the ability to build positive self-efficacy among students of the College Students Council (CSC) so that it can more significant impact on improving life.

\section{Acknowledgments}

Appreciation is shown to be the College Students Council (CSC) in this study and for taking the time to cooperate in completing the questionnaire. Not to forget the UPSI and Department unspoken, thank you for the support in this research.

\section{Reference}

Anderson, B. S., Winett, R. A, \& Wojcik, I. R. (2000). Social-Cognitive Determinants of Nutrition Behavior among Supermarket Food Shoppers: A Structural Equation Analysis. Journal of Health Psychology, 19(5), 479-486. doi:10.1037/02786133.19.5.479

Annesi, J. J, Unruh, J. L, Marti, C. N, Gorjala, S., Tennant, G. (2011). Effects of the coach approach intervention on adherence to exercise in obese women: assessing mediation of social cognitive theory factors. Research Quarterly Exercise Sport, 82(1), 99-108. doi:10.1080/02701367.2011.10599726

Armitage, C. J., \& Conner, M. (2001). Efficacy of the Theory of Planned Behaviour : A meta-analytic review. British Journal of Social Psychology, 40, 471-499. doi:10.1348/014466601164939

Bandura, A. (1982). Self-Efficacy Mechanism in Human Agency. American Psychological Association, 37(2), 122-147. doi:10.1037/0003-066X.37.2.122

Bandura, A., \& Locke, E. A. (2003). Negative Self-Efficacy and Goal Effects Revisited. Journal of Applied Psychology, 88(1), 87-99. doi:10.1037/0021-9010.88.1.87

Bangcola, A. A. (n.d.). Learning Styles as Predictor of Academic Performance in the Nursing Department of an Asian University and Colleges. International Journal of Learning, Teaching and Educational Research, 15(4), 22-31.

Bentsen, P., \& Jensen, F. S. (2012). The nature of udeskole : outdoor learning theory and practice in Danish schools. Journal of Adventure Education \& Outdoor Learning, 12(3), 37-41. doi:10.1080/14729679.2012.699806

Blatti, T., Clinton, J., \& Graham, L. (2019). Exploring collective teacher efficacy in an international school in Shanghai. International Journal of Learning, Teaching and Educational Research, 18(6), 214-235. doi:10.26803/ijlter.18.6.13

Bong, M., \& Skaalvik, E. M. (2003). Academic Self-Concept and Self-Efficacy: How Different Are They Really? Educational Psychology Review, 15(1), 1-40. doi:10.1023/A:1021302408382

Carlson, K. P., \& Cook, M. (2007). Challenge by Choice: Adventure-Based Counseling for Seriously Ill Adolescents. Child Adolesc Psychiatric Clin N Am, 16(4), 909-919. doi:10.1016/j.chc.2007.05.002

Chahine, I. C. (2015). Improving the Quality of Learning Outcomes and Enhancing the Performance of Education Systems: A Case Study in Kuwait. International Journal of Learning, Teaching and Educational Research, 10(1), 1-21. doi:10.5339/qfarc.2016.SSHAPP2009 
Chen, G., \& Gully, S. M. (2001). Validation of a New General Self-Efficacy Scale. Organizational Research Methods, 4(1), 62-83. doi:10.1177/109442810141004

City, N. T. (2015). Efficacy of Cognitive Instruction in Teaching Deictic Motion Verbs in EFL Classrooms. International Journal of Learning, Teaching and Educational Research, 12(1), 84-104.

Duindam, T. (1994). Perspectives: Experiential education and outdoor adventure in the Netherlands. The Journal of Experiential Education, 17(3), 24-27. doi:10.1177/105382599401700309

Elstad, E. (2017). Teachers' Self-Efficacy at Maintaining Order and Discipline in Technology-Rich Classrooms with Relation to Strain Factors. International Journal of Learning, Teaching and Educational Research, 16(1), 103-119.

Flammer, A. (2015). Self-Efficacy. International Encyclopedia of Social \& Behavioral Sciences, 504-508. doi:10.1016/B978-0-08-097086-8.25033-2

Gillen, M. C., \& Balkin, R. S. (2010). Adventure Counseling as an Adjunct to Group Counseling in Hospital and Clinical Settings. The Journal for Specialists in Group Work, 31(2), 153-164.. doi:10.1080/01933920500493746

Greason, P. B., \& Cashwell, C. S. (2009). Mindfulness and Counseling Self-Efficacy: The Mediating Role of Attention and Empathy. Counselor Education and Supervision, 49(1), 2-19. doi:10.1002/j.1556-6978.2009.tb00083.x

Hermans, H. J. M. (2014). Self as a Society of I-Positions: A Dialogical Approach to Counseling. Journal of Humanistic Counseling, 53(2), 134-159. doi:10.1002/j.21611939.2014.00054.x

Lee, N. K. (2015). Efficacy of motivational interviewing and cognitive behavioral therapy for anxiety and depression symptoms following traumatic brain injury Efficacy of motivational interviewing and cognitive behavioral therapy for anxiety and depression symptoms follow. Psychological Medicine, 4(5), 1079-1090. doi:10.1017/S0033291715002640

Marx, J. D. (1988). An Outdoor Adventure Counseling Program for Adolescents. National Association of Social Workers, 33(6), 517-520. doi:10.1093/sw/33.6.517

Nowak, B. M. (2019). The Sense of Self-Efficacy of Teachers Working in Special Schools A Research Communiqué. International Journal of Learning, Teaching and Educational Research, 18(10), 161-174. doi:10.26803/ijlter.18.10.10

Ottander, C., Wilhelmsson, B., \& Lidestav, G. (2015). Teachers "Intentions for Outdoor Learning: A Characterisation of Teachers "Objectives and Actions. International Journal of Learning, Teaching and Educational Research, 13(3), 208-230.

People, A. B. (2017). Exercise of personal and collective efficacy in changing societies. Self-Efficacy in Changing Societies, 1-45. doi:10.1017/CBO9780511527692.003

Ragsdale, K. G., Cox, R. D., Finn, P., \& Eisler, R. M. (1996). Effectiveness of Short-Term Specialized Inpatient Treatment for War-Related Posttraumatic Stress Disorder : A Role for Adventure-Based Counseling and Psychodrama. Journal of Traumatic Stress, 9(2), 269-283. doi:10.1007/bf02110660

Rhodes, C. M., Cordie, L., \& Wooten, M. (2019). An examination of social capital among U.S. Adults: Patterns that facilitate social well-being as measured by PIAAC. International Journal of Learning, Teaching and Educational Research, 18(2), 1-12. doi:10.26803/ijlter.18.2.1

Roth, R. L. (2016). The Socratic Method Reloaded: a Rereading to Improve a Technologically Sound Education. International Journal of Learning, Teaching and Educational Research, 15(6), 1-32.

Rusmana, N. and D. S. (2019). A quasi experiment on group exercises to improve students ' resilience. Journal of Physics: Conference Series, 1318, 012128. doi:10.1088/1742-6596/1318/1/012128 
Sidiropoulou-dimakakou, D., \& Mylonas, K. (2015). Self-Efficacy in Career Planning: A New Approach to Career Exploration. International Journal of Learning, Teaching and Educational Research, 11(2), 40-54.

Sparks, P., Ajzen, I., \& Hall-box, T. (2002). Perceived Behavioral Control, Self-Efficacy , Locus of Control, and the Theory of Planned Behavior. Journal of Applied Social Psychology, 32(4), 665-683. doi:10.1111/j.1559-1816.2002.tb00236.x

Stajkovic, A. D., \& Luthans, F. (1998). Self-Efficacy and Work-Related Performance: A Meta-Analysis. American Psychological Association, 124(2), 240-261. doi:10.1037/0033-2909.124.2.240

Taft, R. J., Hotchkiss, J. L., \& Lee, D. (2016). Efficacy of Music Therapy and Bibliotherapy as Interventions in the Treatment of Children With EBD : A Literature Review. International Journal of Learning, Teaching and Educational Research, 15(10), 113-129.

Taufik, A., Yudha, E. S., \& Suryana, D. (2019). The Raven' s Advanced Progressive Matrices in Education Assessment with a Rasch Analysis. Universal Journal of Educational Research, 7(9), 1996-2002. doi:10.13189/ujer.2019.070921

Tho, P., Dong, L., \& Noi, H. (2015). Designing a Classification Toolkit for Mathematically-Deficient 4 th Grade Students: A Case Study in Vietnam. International Journal of Learning, Teaching and Educational Research, 14(2), 68-86.

Werner, K. M., \& Milyavskaya, M. (2018). Motivation and self-regulation: The role of want to motivation in the processes underlying self-regulation and self-control. Social and Personality Psychology Compass, e12425. doi:10.1111/spc3.12425 